\title{
The applicability of the Eating Disorder Inventory in pregnancy
}

\author{
Szilvia Dukay-Szabó ${ }^{1}$ (1) - Dávid Simon ${ }^{2} \cdot$ Márta Varga $^{3} \cdot$ Orsolya Koller $^{4} \cdot$ Zoltán Pataki $^{5} \cdot$ János Rigó Jr. $^{6,7}$. \\ Ferenc Túry ${ }^{4}$
}

Received: 11 January 2021 / Accepted: 15 April 2021 / Published online: 7 May 2021

(c) The Author(s) 2021

\begin{abstract}
Purpose The aim of our study was validating Eating Disorder Inventory (EDI) among pregnant women, who are vulnerable to eating disorders (EDs).

Methods In 2012-2013, 1146 women (aged 18-47 years) completed a questionnaire including EDI during the first 3 days after delivery. We checked factorial validity of three diagnostic subscales of EDI with confirmative factor analysis and internal validity by Cronbach's alpha and item-total correlation. We also tested discriminative validity by comparing average of the three subscale of EDI in case of ED and non-ED groups.

Results When applying the EDI to pregnant women, it seems necessary to exclude five items on three diagnostic subscales: on the Drive for Thinness subscale, 4 items remain (out of 7); on the Bulimia subscale, 6 items remain (out of 7); the Body Dissatisfaction subscale decreases from 9 to 8 items. Cronbach's alpha and item-total correlation values meet the requirements defined by Garner et al. The internal consistency of the EDI has proved to be appropriate, indicating that it is a reliable screening tool.

Conclusions Thinking, attitudes, and behaviors connected to eating, along with the relation to altering body weight change during pregnancy. Vomiting usually accompanies pregnancy; body weight gain within wide limits is also regarded as normal during pregnancy. These behaviors and changes are not feasible to use for measuring ED symptoms. These aspects cannot be neglected when screening eating disorders in pregnant women.
\end{abstract}

Level of evidence Level IV evidence obtained from multiple time series with or without an intervention.

Keywords Eating disorders $\cdot$ Pregnancy $\cdot$ Eating disorder inventory $\cdot$ Validity $\cdot$ Reliability

Szilvia Dukay-Szabó

dukayszaboszilvia@gmail.com

1 Institute of Behavioural Sciences, Doctoral School of Mental Health Sciences, Semmelweis University, Nagyvárad tér 4, 1089 Budapest, Hungary

2 Faculty of Social Sciences, Eötvös Loránd University, Budapest, Hungary

3 Faculty of Humanities and Social Sciences, Pázmány Péter Catholic University, Budapest, Hungary

4 Institute of Behavioural Sciences, Semmelweis University, Budapest, Hungary

5 Uzsoki Hospital, Budapest, Hungary

6 Department of Obstetrics and Gynaecology, Semmelweis University, Budapest, Hungary

7 Department of Clinical Studies in Obstetrics and Gynaecology, Semmelweis University, Budapest, Hungary

\section{Introduction}

Eating disorders (EDs) have become increasingly frequent since the middle of the last century [1]. In addition to individual factors, the social environment plays a significant part in their occurrence. The spectrum of eating disorders has broadened, and new conditions are constantly appearing. Together with obesity, eating disorders are now a major issue in public health [2]. Since the early recognition of a disorder is one of the most important criteria for a good prognosis [3], there is a great need for easy-to-use screening methods.

EDs connected with pregnancy have a special importance for at least three reasons. First, the onset of the EDs occurs typically in adolescence or in young adulthood among women at a critical phase of women's reproductive life [4], and it appears among 7.5-11.5\% of pregnant women) [5, 6]. Second, EDs regularly involve a lack of insight or the hiding 
of somatic symptoms, and psychological factors make diagnosis more difficult in case of pregnancy [7]. Third, among women in these age groups, psychosomatic disorders can have numerous consequences for pregnancy, its outcome, the development of the fetus, and the postpartum period [6, $8-11]$. In addition to the classic eating disorders (anorexia nervosa, bulimia nervosa, and binge eating disorder), a condition specifically associated with pregnancy: pregorexia, which is used to describe women who try to reduce weight gain by dieting and exercising to avoid obesity and retain their slender shape has also been described [12]. Despite the presence of this phenomenon, however, the problem in the developed world is not primarily malnutrition, but excessive weight gain and obesity. [2, 12]. Accordingly, screening for EDs among women in pregnancy is of crucial importance.

Physiological changes and events of the pregnancy can cause problems and biases in screening pregnant women for EDs [13]. Although there are general screening tools for mental disorders that have already been validated among pregnant women [14], and a Delphi consensus study investigated possible items recognizing symptoms of disordered eating [15], to our knowledge, this has not been done for any ED specific measure. This article focuses on the three symptom-related diagnostic EDI subscales for which physiological changes during pregnancy are most likely to cause interference (Drive for Thinness, Body Dissatisfaction, and Bulimia subscales).

The EDI was developed by Garner and colleagues in 1983 [16], and according to recent review studies [17-19], it is one of the most widely used instruments both for the assessment of symptoms and evaluation of treatment effect in clinical practice and for research. Garner et al. validated EDI by checking internal consistency (by Cronbach alpha), criterion-related validity (comparing ED and non-ED groups), and convergent and discriminant validity (based on correlation with other scales) [16]. A meta-analysis conducted by Gleaves et al. [20] proved high reliability of EDI by analyzing published Cronbach alphas. More recently, there have been detailed analyses of the dimensionality [21, 22] and discriminant validity [23] of EDI. Evaluation of EDI has been repeated successfully in different countries (e.g., Austria [24], Hong Kong [25], Hungary [26], and Sweden [27]) and in different subpopulations (e.g., adolescents [28] and athletes [29]), but the evaluation has not been repeated among pregnant women.

The aim of our paper is to validate the widely used Eating Disorder Inventory (EDI) among pregnant women, a specific population which is vulnerable to eating disorders. The topicality and significance of the issue is yielded by the fact that among young women, the incidence of eating disorders is high and it also appears among pregnant women. Since pregnancy is associated with both physical and mental changes, and some of these changes manifest themselves in
Table 1 Demographic and anthropometric data of the respondents

\begin{tabular}{|c|c|c|}
\hline & $N$ & $\%$ \\
\hline Total & 1146 & 100.0 \\
\hline \multicolumn{3}{|l|}{ Age groups } \\
\hline Below 26 years & 109 & 9.5 \\
\hline $26-30$ years & 300 & 26.2 \\
\hline $31-35$ years & 403 & 35.2 \\
\hline Above 35 years & 315 & 27.5 \\
\hline No data & 19 & 1.7 \\
\hline Mean age (years $\langle\mathrm{SD}\rangle ;$ [range]) & \multicolumn{2}{|c|}{32.1 years $\langle 5.16\rangle[18-47]$} \\
\hline \multicolumn{3}{|l|}{ Qualification } \\
\hline Primary education & 69 & 6.0 \\
\hline $\begin{array}{l}\text { Secondary education with vocational } \\
\text { training }\end{array}$ & 86 & 7.5 \\
\hline Secondary education with final exams & 367 & 32.0 \\
\hline College/university degree & 621 & 54.2 \\
\hline No data & 3 & 0.3 \\
\hline \multicolumn{3}{|l|}{ Type of settlement } \\
\hline Budapest & 574 & 50.1 \\
\hline City or town & 395 & 34.5 \\
\hline Village & 169 & 17.0 \\
\hline No data & 8 & 0.7 \\
\hline \multicolumn{3}{|l|}{ Before pregnancy } \\
\hline Underweight $(\mathrm{BMI}<18.5)$ & 81 & 7.1 \\
\hline Normal weight $(18.5 \leq \mathrm{BMI}<25)$ & 729 & 63.6 \\
\hline Overweight $(25 \leq \mathrm{BMI}<30)$ & 211 & 18.4 \\
\hline Obese (BMI $\geq 30)$ & 103 & 9.0 \\
\hline No data & 22 & 1.9 \\
\hline Mean BMI $\left(\mathrm{kg} / \mathrm{m}^{2}\langle\mathrm{SD}\rangle ;\right.$ [range] $)$ & \multicolumn{2}{|c|}{$\begin{array}{l}23.41 \mathrm{~kg} / \mathrm{m}^{2}\langle 4.63\rangle[15.4- \\
\quad 47.8]\end{array}$} \\
\hline
\end{tabular}

forms similar to eating disorder symptoms, the validation of the measure should be repeated in the pregnant population.

\section{Method}

\section{Participants}

We conducted a cross-sectional survey in the 1st Department of Obstetrics and Gynaecology, Semmelweis University, Budapest, between May 2012 and April 2013. All mothers included in the research had had full-term pregnancies, their infants were healthy, and they were able to read and write in Hungarian. Mothers of stillbirths or of infants placed in the intensive-care unit were excluded. Participation was voluntary, and all the participants signed an informed consent. Nurses employed in the puerperal department distributed and collected the survey materials, which increased compliance. The women received the questionnaire immediately 
after delivery and completed it no later than 3 days, while they were in the maternity ward.

Ethical permission was given by the Semmelweis University Regional and Institutional Committee of Science and Research Ethics (Nr 12631/2012/EKU. (212/PI/12.)).

The questionnaire was filled by 1146 women altogether (the overall response rate was $88.2 \%$ ). The mean age of the respondents was 32.1 years $(\mathrm{sd}=5.16$ with a range of 18-47 years). Table 1 shows the distribution of the sample.

\section{Measures}

Our retrospective questionnaire contained items about demographic and anthropometric data, feelings and attitudes related to body weight, body shape, and their changes during pregnancy, history of former pregnancies, details of the last pregnancy, lifestyle before and during pregnancy, as well as detailed questions on eating habits and the respondent's relation to eating and her own body in the past 3-6 months.

Identification of EDs was based on self-reporting. We defined the ED group according to whether respondents reported experiencing any somatic or psychological symptoms of EDs: we asked the women in the study whether they had ever had an ED in their lifetime, 1 year before pregnancy or during pregnancy. The ED group comprised women who reported that they had an ED during their pregnancy. Among the respondents, 84 (7.3\%) had been affected by ED at some time during their lives, based on self-report, of whom 58 (5.1\%) stated that they had had EDs sometime in the past (the ex-ED group) and 26 (2.2\%) were currently experiencing ED (the ED group), while 1054 (92\%) were stated that they had not suffered from ED at all (the non-ED group). Eight mothers did not respond to this question. (See Table 2.)

The questionnaire contained translations of the three diagnostic subscales of EDI. Each item of EDI is measured by 6-point Likert scale (always, usually, often, sometimes, rarely, or never), scoring $0-3$, where higher scores represents more severe symptoms. The diagnostic subscales are the following: Drive for Thinness subscale (7 items), Body Dissatisfaction subscale (7 items), and Bulimia subscale (9 items). The Hungarian translation of EDI was evaluated for general population by Túry et al. [26].

\section{Statistical analysis}

We used IBM SPSS 23 statistical package. 129 questionnaires not completed properly in respect of EDI were excluded from the analysis. Questionnaires were included where the answers were given either in terms of lifetime or point prevalence. Since incomplete questionnaires were included, the number of cases in different aspects of analysis can vary.

We checked the internal consistency of the EDI subscales by Cronbach's alpha and item-total correlations (ITC). For desirable thresholds, Garner and colleagues considered having the coefficients of internal consistency (Cronbach's alpha) above .80 for the ED subsample, and item-scale

Table 2 Distribution of self-reported eating disorders in the sample

\begin{tabular}{|c|c|c|}
\hline & $N$ & $\%$ \\
\hline Total & 1146 & 100.00 \\
\hline Self-reported eating disorder during the last pregnancy or in the past altogether & 84 & 7.33 \\
\hline$A N$ & 19 & 1.66 \\
\hline$B N$ & 13 & 1.13 \\
\hline EDNOS & 46 & 4.01 \\
\hline No data about the type & 6 & 0.52 \\
\hline People having had an eating disorder in the past & 58 & 5.06 \\
\hline Having had an eating disorder in the past and in connection with pregnancy & 2 & 0.17 \\
\hline Having had an eating disorder in connection with pregnancy but not in the past & 24 & 2.09 \\
\hline No data by self-report & 8 & $\mathbf{0 . 7 0}$ \\
\hline Not reported any eating disorders either in the last pregnancy or in the past & 1054 & 91.97 \\
\hline
\end{tabular}

Bold values are as the title says: "distribution of self-reported eating disorders in the sample"

Italic values: the distribution of the 84 affected respondents according to eating disorder type

Regular values: the distribution of the 84 affected respondents according to time of occurence of the eating disorders 
correlation coefficients above .40 . They accepted ITC below .40 in several cases they considered conceptually important. We tested whether ITC and Cronbach's alpha values in the ED subsample met the above-mentioned criteria.
We checked the factorial validity of the three diagnostic subscales of the EDI with confirmative factor analysis (CFA; similarly to Espelage et al [22]). We compared the three-factor model to the null model and one-factor model, and initially, we assumed uncorrelated errors. Considering

Table 3 Item-total correlations of EDI items and Cronbach's alpha values of EDI subscales

\begin{tabular}{|c|c|c|c|c|c|c|c|c|c|c|}
\hline & \multirow[b]{3}{*}{ Drive for Thinness } & \multicolumn{2}{|c|}{ Garner et al* } & \multirow{2}{*}{\multicolumn{2}{|c|}{$\begin{array}{c}\text { Whole sample } \\
(\mathrm{N}=1017)\end{array}$}} & \multirow{2}{*}{\multicolumn{4}{|c|}{ ED group $(\mathrm{N}=26)$}} & \multirow{3}{*}{\begin{tabular}{|c}
$\begin{array}{c}\text { Final } \\
\text { EDI } \\
\text { structu } \\
\text { re }\end{array}$ \\
All
\end{tabular}} \\
\hline & & \multirow[t]{2}{*}{$\mathbf{A N}$} & \multirow[t]{2}{*}{ FC } & & & & & & & \\
\hline & & & & & & & & & & \\
\hline $1^{*}$ & $\begin{array}{l}\text { I eat sweets and carbohydrates without feeling } \\
\text { nervous. }\end{array}$ & 0.32 & 0.37 & 0.08 & - & 0.12 & - & - & - & - \\
\hline 7 & I think about dieting. & 0.76 & 0.66 & 0.43 & 0.44 & 0.24 & 0.17 & - & - & - \\
\hline 11 & I feel extremely guilty after overeating. & 0.58 & 0.63 & 0.46 & 0.51 & 0.69 & 0.80 & 0.79 & 0.80 & 0.50 \\
\hline 16 & I am terrified of gaining weight. & 0.76 & 0.67 & 0.60 & 0.65 & 0.78 & 0.79 & 0.79 & 0.86 & 0.63 \\
\hline 25 & I exaggerate or magnify the importance of weight. & 0.43 & 0.59 & 0.45 & 0.48 & 0.21 & 0.29 & 0.29 & - & - \\
\hline 32 & I am preoccupied with the desire to be thinner. & 0.66 & 0.74 & 0.59 & 0.64 & 0.74 & 0.80 & 0.78 & 0.82 & 0.61 \\
\hline \multirow[t]{3}{*}{49} & If I gain a pound, I worry that I will keep gaining. & 0.70 & 0.66 & 0.54 & 0.56 & 0.54 & 0.46 & 0.50 & 0.48 & 0.54 \\
\hline & Cronbach's alpha & 0.85 & 0.85 & 0.70 & 0.79 & 0.76 & 0.80 & 0.83 & 0.88 & 0.77 \\
\hline & Bulimia & & & & & & & & & \\
\hline 4 & I eat when I am upset. & 0.58 & 0.51 & 0.37 & 0.40 & 0.55 & - & - & - & 0.40 \\
\hline 5 & I stuff myself with food. & 0.79 & 0.53 & 0.52 & 0.54 & 0.51 & - & - & - & 0.54 \\
\hline 28 & $\begin{array}{l}\text { I have gone on eating binges where I have felt that } \\
\text { I could not stop. }\end{array}$ & 0.69 & 0.64 & 0.44 & 0.44 & 0.49 & - & - & - & 0.44 \\
\hline 38 & I think about bingeing (overeating). & 0.74 & 0.60 & 0.51 & 0.50 & 0.66 & - & - & - & 0.50 \\
\hline 46 & $\begin{array}{l}\text { I eat moderately in front of others and stuff myself } \\
\text { when they're gone. }\end{array}$ & 0.75 & 0.67 & 0.60 & 0.59 & 0.74 & - & - & - & 0.59 \\
\hline 53 & $\begin{array}{l}\text { I have the thought of trying to vomit in order to } \\
\text { lose weight. }\end{array}$ & 0.70 & 0.42 & 0.19 & - & 0.65 & - & - & - & - \\
\hline \multirow[t]{3}{*}{61} & I eat or drink in secrecy. & 0.73 & 0.60 & 0.45 & 0.43 & 0.64 & - & - & - & 0.43 \\
\hline & Cronbach's alpha & 0.90 & 0.83 & 0.71 & 0.72 & 0.81 & - & - & - & 0.72 \\
\hline & Body dissatisfaction & & & & & & & & & \\
\hline 2 & I think that my stomach is too big. & 0.51 & 0.51 & 0.38 & - & 0.67 & & & & - \\
\hline 9 & I think that my thighs are too large. & 0.69 & 0.68 & 0.63 & 0.63 & 0.71 & - & - & - & 0.63 \\
\hline $12 *$ & I thing that my stomach is just the right size. & 0.66 & 0.58 & 0.45 & 0.43 & 0.70 & - & - & - & 0.43 \\
\hline $19 *$ & I feel satisfied with the shape of my body. & 0.50 & 0.65 & 0.67 & 0.67 & 0.86 & - & - & - & 0.67 \\
\hline $31^{*}$ & I like the shape of my buttocks. & 0.69 & 0.68 & 0.59 & 0.60 & 0.43 & - & - & - & 0.60 \\
\hline 45 & I think my hips are too big. & 0.78 & 0.75 & 0.60 & 0.59 & 0.66 & - & - & - & 0.59 \\
\hline $55^{*}$ & I think that my thighs are just the right size. & 0.73 & 0.78 & 0.71 & 0.72 & 0.63 & - & - & - & 0.72 \\
\hline 59 & I think my buttocks are too large. & 0.83 & 0.73 & 0.63 & 0.62 & 0.64 & - & - & - & 0.62 \\
\hline \multirow[t]{2}{*}{$62 *$} & I think that my hips are just the right size. & 0.70 & 0.78 & 0.67 & 0.68 & 0.81 & - & - & - & 0.68 \\
\hline & Cronbach's alpha & 0.90 & 0.91 & 0.86 & 0.87 & 0.90 & - & - & - & 0.87 \\
\hline
\end{tabular}

* Garner: AN group $\mathrm{N}=113$, FC (female control) $\mathrm{N}=577$. 
the significantly skewed distribution of the scales, we used maximum-likelihood estimation with bootstrap method (1000 resample). We measured the model fit with TLI and RMSEA: for the first three measures, we used the minimum threshold of .9, according to Klein [30], and for the last one, the maximum threshold of .08 according to Quintana and Maxwell [31]).

We also measured the discriminative validity of EDI by comparing scores between ED and non-ED groups on the three subscales. As the distributions of the subscales were non-normal and the group with EDs was small, we used a non-parametric test (Mann-Whitney U) for the comparison.

\section{Results}

The internal consistency analysis showed that several items of the EDI gave inconsistent results in the analyzed sample (Table 3). To be sufficiently sensitive, the measurement has to be consistent in the group of people with EDs, and to yield specific results, the measurements must be consistent in the whole sample. We paid due heed to these considerations when deciding whether to keep or exclude an item.

The first item on the Drive for Thinness subscale "I eat sweets and carbohydrates without feeling nervous" did not properly correspond to the subscale for either participants with EDs or the sample of pregnant women as a whole (ITC values were .12 and .08 , which were considerably below the .4 threshold). Furthermore, in the case of participants with EDs the item "I think about dieting" and "I exaggerate or magnify the importance of weight" did not correlate to the subscale we intended to investigate (ITC $=.17$ and .29 ). This subscale was therefore narrowed down to four items. Cronbach's alpha for the subscale was .77 on the whole sample and .88 on the ED subsample, and ITC values for each item were above .4. Consequently, the subscale was found to measure consistently. The exclusion of items also improved the reliability of the measurement.

On the Bulimia subscale, the item "I have the thought of trying to vomit in order to lose weight" was inconsistent in the whole pregnant sample (ITC $=.19$ ). It would have fitted properly in the ED subsample $(\mathrm{ITC}=.65)$, but since it measured inconsistently in the whole sample, we decided to exclude the item, reducing the Bulimia subscale to six items. Now Cronbach's alpha was .72 on the whole and. 8 in the ED subsample, and ITC values to each item reached or exceeded 4 .

On the Body Dissatisfaction subscale, we excluded an item for the same reason. The statement "I think that my stomach is too big" did not match properly to the other items of the subscale in the whole sample (ITC $=.38$ ), so we left it out in spite of the fact that it would have worked well in the ED subsample $(\mathrm{ITC}=.67)$. Finally, the subscale was reduced to eight items and resulted in the highest Cronbach's alpha

Table 5 EDI item factor loadings for confirmatory factor analysis of corrected three-factor model

\begin{tabular}{|c|c|c|c|c|}
\hline \multirow[t]{2}{*}{ Item } & \multicolumn{4}{|c|}{ Factor loading (bootstrap estimation) } \\
\hline & Estimate & Lower & Upper & $P$ \\
\hline \multicolumn{5}{|l|}{ DT } \\
\hline 11 & .59 & .49 & .68 & .003 \\
\hline 16 & .72 & .64 & .78 & .003 \\
\hline 32 & .78 & .72 & .83 & .002 \\
\hline 49 & .63 & .51 & .72 & .003 \\
\hline \multicolumn{5}{|l|}{ BUL } \\
\hline 4 & .52 & .33 & .67 & .001 \\
\hline 5 & .65 & .35 & .80 & .001 \\
\hline 28 & .50 & .21 & .70 & .006 \\
\hline 38 & .58 & .22 & .79 & .002 \\
\hline 46 & .69 & .34 & .85 & .003 \\
\hline 61 & .55 & .12 & .84 & .003 \\
\hline \multicolumn{5}{|c|}{ BODIS } \\
\hline 9 & .79 & .75 & .83 & .002 \\
\hline $12 *$ & .47 & .41 & .54 & .001 \\
\hline $19 *$ & .76 & .71 & .79 & .002 \\
\hline $31 *$ & .59 & .54 & .65 & .002 \\
\hline 45 & .63 & .56 & .69 & .002 \\
\hline $55^{*}$ & .78 & .75 & .81 & .002 \\
\hline 59 & .65 & .59 & .71 & .002 \\
\hline $62 *$ & .75 & .70 & .79 & .001 \\
\hline
\end{tabular}

*Items were reversed

Errors for the following items were correlated: 9 and 19; 45 and 59; 9 and 62
Table 4 Goodness-of-fit indicators for EDI confirmatory factor analysis models

\begin{tabular}{lllllll}
\hline Model & GFI & AGFI & $X^{2}$ & $X^{2} / \mathrm{dfs}$ & CFI & RMSEA \\
\hline Null & .38 & .31 & 6418.65 & 41.95 & .00 & .21 \\
One factor & .78 & .72 & 1888.38 & 14.31 & .72 & .12 \\
Three factor & .86 & .83 & 1656.41 & 7.30 & .81 & .08 \\
Corrected three factor $^{\mathrm{a}}$ & .92 & .89 & 783.95 & 6.08 & .90 & .07 \\
\hline
\end{tabular}

${ }^{a}$ Following items were removed, due to low internal consistency: 1, 2, 7, 25, and 53. Errors for the following items were correlated: 9 and $19 ; 45$ and 59; 9 and 62 
Table 6 Inter-scale correlation for confirmatory factor analysis of corrected three-factor model

\begin{tabular}{lllll}
\hline Scales & Estimate & Lower & Upper & $P$ \\
\hline DT-BUL & .47 & .31 & .60 & .003 \\
DT-BODIS & .70 & .63 & .75 & .002 \\
BUL-BODIS & .30 & .21 & .39 & .001 \\
\hline
\end{tabular}

value: .87 in the whole sample and .90 in the ED subsample. Item-total correlations were over .4 in case of every items.

The three-factor CFA model, as shown in Table 4, did not fit the data $(\mathrm{GFI}=.86 ; \mathrm{AGFI}=.83 ; \mathrm{CFI}=.81 \mathrm{RMSEA}=.08)$. We also found that the three-factor model fitted our data much better than the null model or the one-factor model. After excluding the above five items, we fitted the threefactor CFA models again. To obtain a better fit in the case of Body Dissatisfaction, we had to allow correlation between three pairs of items (which are all semantically related to each other). Having made these changes, the fit of the model was acceptable (GFI $=.92$; $\mathrm{AGFI}=.89$; $\mathrm{CFI}=.90$; RMSEA $=.07$; Table 4 ). The factor scores are presented in Table 5, and the inter-scale correlations in Table 6.

The diagnostic cut-off values for the three subscales were adjusted proportionally to adjust for the five excluded items. The proposed cut-off values are: 8 points on the Drive for Thinness subscale, 12 points on the Bulimia subscale, and 19 points on the Body Dissatisfaction subscale for the population of pregnant women.

We found a significant difference between ED and nonED subsamples on every subscale of the EDI validated on the pregnant population (Table 7). In the absence of a clinical diagnosis, we cannot calculate exact sensitivity values, but the difference between the means indicates that subscales of the EDI (reduced by altogether five items) capture those differences in thinking and behavior that Garner and his coresearchers intended to measure.

\section{Discussion}

EDs can cause several prenatal, perinatal, and postnatal sequelae: among others, a higher risk for complicated course of pregnancy, miscarriage, cesarean section, poor fetal growth, postpartum depression, and breastfeeding difficulties $[6,8,9,32]$. Since these phenomena influence the health of both mother and infant, it is essential to recognize these psychosomatic disorders as early as possible. Furthermore, because of the shame and secretiveness characteristic of this condition, and since diagnosis cannot be established before pregnancy, a valid screening tool is necessary during pregnancy. The aim of this study was to validate the EDI questionnaire in a pregnant population, using all the three diagnostic subscales of the test. As for field work, we used self-report questionnaires, which lack the stringency of a diagnostic interview but offer the benefits of anonymity. Because of their hidden character, EDs are almost certainly underreported. Anonymity increases the probability of a more realistic picture of the occurrence of symptoms, a view that is reinforced by the satisfactorily high response rate of this survey, although this must be set against the loss of diagnostic accuracy. Although the sample was not random, it was representative in an important respect: the BMI distribution of the respondents was similar to that of the female respondents of the same age in a Hungarian representative survey [33].

We surveyed 1146 women who had given birth following full-term pregnancies. The results show that certain items of the EDI function differently on a sample of pregnant women than on an average sample. To validate the EDI on a pregnant population, we needed to exclude five items-three from the Drive for Thinness subscale and one each from the Bulimia and Body Dissatisfaction subscales.

All the excluded items are clearly linked to changes in the physiological or psychological state of pregnant women, which probably accounts for these items' limited usability. The three items removed from Drive for Thinness subscale are closely related to increased food consumption without feeling less stress during pregnancy, as found by Clark and Ogden [34]. One item ("I think about dieting") might also be related to the increased drive towards healthy behavior observed among pregnant women. The answers to the item that was removed from the Bulimia subscale ("I have the thought of trying to vomit in order to lose weight") might have been affected by the increase in the prevalence of nausea during pregnancy described by Lacroix et al [35]. In this case, vomiting can be caused by an ED but also can be a normal accompaniment of being pregnant. Finally, the
Table 7 EDI mean scores in ED and non-ED groups (nonparametric Mann-Whitney $U$ test)

\begin{tabular}{|c|c|c|c|c|}
\hline \multirow[t]{2}{*}{$\begin{array}{l}\text { Name of the subscale (number of current } \\
\text { ED cases/non-ED cases) }\end{array}$} & \multicolumn{2}{|l|}{ Mean (SD) } & \multicolumn{2}{|c|}{$\begin{array}{l}\text { Mann-Whitney } \\
U \text { test }\end{array}$} \\
\hline & ED group & Non-ED group & $U$ & $p$ \\
\hline EDI-Drive for thinness $(23 / 1025)$ & $3.26(4.06)$ & $0.97(2.00)$ & 15,703 & .001 \\
\hline EDI-Bulimia $(25 / 1052)$ & $1.12(2.15)$ & $0.13(0.75)$ & 16,659 & .000 \\
\hline EDI-Body dissatisfaction (24/1033) & $9.08(6.70)$ & $5.40(5.29)$ & 16,570 & .005 \\
\hline
\end{tabular}


answers to the item that was removed from the Body Dissatisfaction subscale ("I think that my stomach is too big") could have been heavily biased by the physiological change in the shape of abdomen during pregnancy. Since the swelling of the abdomen is a natural concomitant of pregnancy, it is less likely to be perceived as a problem.

After this modification, the internal consistency of the EDI was satisfactory and it appeared to be a reliable screening tool. Cronbach's alpha and item-total correlation values reached or exceeded the required thresholds. The differences between means on the EDI subscales showed that the test effectively measures dimensions of EDs and is thus capable of discriminating between ED and non-ED patients. However, due to the self-reporting and the fact that the reference group did not properly correspond to the target group, we could not calculate exact sensitivity and specificity.

Our results show partial similarity to the Delphi consensus study conducted among health professionals and women during or after pregnancy [15]. The Delphi consensus study showed that urges of wanting to vomit was a non-consensus item, which is similar to our finding on the inconsistency of the vomit-related item of EDI Bulimia subscale. On the other hand, distress regarding changing shape was a consensus item that is conflicting with our finding on the inconsistency of stomach size-related item of EDI Body Dissatisfaction subscale.

The results confirm that attitudes and cognitions connected to eating and attitudes to changing body weight alter during pregnancy, and these alterations have a physiological background. New forms of responsibility appear, and we can see a realignment of priorities (expecting a baby versus having an ED) [36, 37].

Changing behavior and attitudes during pregnancy improve body satisfaction and decrease the urge to control food intake. In most cases, physical symptoms of EDs moderate or disappear during pregnancy [37]. Because vomiting accompanies pregnancy, it is no longer a tool for body weight manipulation.

Earlier research has found that pregnancy can have diverse effects on ED symptoms: in some cases, pregnancy functions as a healing tool, and in others, symptom severity decreases but recurs after delivery, while in a third group, symptoms maintain during pregnancy and in the postpartum period [38].

\section{Limitations}

The aim of our study was to evaluate EDI among pregnant women. Data were collected after delivery, during the first 3 days of the postpartum period. To adjust data, measurement was based on retrospective questions. The fact that our results showed such kind of deviations from the non-specific population that can be linked to changes in the physiological or psychological state of pregnant women support the validity of our results. Further research should confirm our results based on a survey among pregnant women with non-retrospective question.

\section{Conclusion}

The findings of our research show that the measurability of signs and symptoms of EDs change during pregnancy in parallel with physiological and psychological changes. The validity of well-established and widely used diagnostic tools such as EDI also change. The instrument therefore requires modification. The possible consequences of hidden ED for pregnancy-in addition to its importance in eating disorder therapy - have considerable relevance for prenatal and postnatal care.

What is already known on this subject?

EDs connected with pregnancy have a special importance, because the onset of the EDs occurs at a critical phase of women's reproductive life, psychological factors make diagnosis more difficult in case of pregnancy, and EDs can have numerous consequences for pregnancy. The EDI is one of the most widely used instruments for the assessment of EDs, which was developed and validated by Garner and colleagues. Physiological changes and events of the pregnancy can cause problems in screening pregnant women for EDs.

What your study adds?

Three diagnostic subscales of EDI were modified and evaluated for pregnant population. The evaluated tool can be used in screening hidden EDs among pregnant women.

Funding Open access funding provided by Semmelweis University. This research was unfunded.

Data availability The datasets generated and analyzed during the study are currently not publicly available but are available from the corresponding author on reasonable request.

\section{Declarations}

Conflicts of interest The authors declare no conflict of interest.

Ethics approval Semmelweis University Regional and Institutional Committee of Science and Research Ethics [Nr 12631/2012/EKU. (212/PI/12.)].

Informed consent Informed consent was obtained from all individual participants included in the study.

Open Access This article is licensed under a Creative Commons Attribution 4.0 International License, which permits use, sharing, adaptation, distribution and reproduction in any medium or format, as long as you give appropriate credit to the original author(s) and the source, provide a link to the Creative Commons licence, and indicate if changes 
were made. The images or other third party material in this article are included in the article's Creative Commons licence, unless indicated otherwise in a credit line to the material. If material is not included in the article's Creative Commons licence and your intended use is not permitted by statutory regulation or exceeds the permitted use, you will need to obtain permission directly from the copyright holder. To view a copy of this licence, visit http://creativecommons.org/licenses/by/4.0/.

\section{References}

1. Lucas AR, Crowson CS, O'Fallon WM et al (1999) The ups and downs of anorexia nervosa. Int J Eat Disord. https://doi.org/10. 1002/(SICI)1098-108X(199912)26:4\%3c397:AID-EAT5\%3e3.0. $\mathrm{CO} ; 2-0$

2. Schmidt U, Adan R, Böhm I et al (2016) Eating disorders: the big issue. Lancet Psychiatry 3(4):313-315. https://doi.org/10.1016/ S2215-0366(16)00081-X

3. Austin A, Flynn M, Richards K et al (2020) Duration of untreated eating disorder and relationship to outcomes: a systematic review of the literature. Eur Eat Disorders Rev. https://doi.org/10.1002/ erv. 2745

4. Túry F, Szabó P (2000) A táplálkozási magatartás zavarai: az anorexia nervosa és a bulimia nervosa [Eating disorders: anorexia nervosa and bulimia nervosa]. Budapest, Medicina.

5. Easter A, Bye A, Taborelli E et al (2013) Recognising the symptoms: how common are eating disorders in pregnancy? Eur Eat Disorders Rev. https://doi.org/10.1002/erv.2229

6. Ward VB (2008) Eating disorders in pregnancy. BMJ. https://doi. org/10.1136/bmj.39393.689595.BE

7. Fursland A, Watson HJ (2014) Eating disorders: a hidden phenomenon in outpatient mental health? Int J Eat Disord. https://doi.org/ 10.1002/eat.22205

8. Micali N (2008) Eating disorders and pregnancy. Psychiatry. https://doi.org/10.1016/j.mppsy.2008.02.003

9. Micali N, Treasure J (2009) Biological effects of a maternal ED on pregnancy and foetal development: a review. Eur Eat Disord Rev 17:448-454

10. Franko DL, Blais MA, Becker AE et al (2001) Pregnancy complications and neonatal outcomes in women with eating disorders. Am J Psychiatry. https://doi.org/10.1176/appi.ajp.158.9.1461

11. Kouba S, Hallstrom T, Lindholm C et al (2005) Pregnancy and neonatal outcomes in women with eating disorders. Obstet Gynecol. https://doi.org/10.1097/01.aog.0000148265.90984.c3

12. Mathieu J (2009) What is pregorexia? J Am Diet Assoc. https:// doi.org/10.1016/j.jada.2009.04.021

13. Hodgkinson EL, Smith DM, Wittkowski A (2014) Women's experiences of their pregnancy and postpartum body image: a systematic review and meta-synthesis. BMC Pregnancy Childbirth. https://doi.org/10.1186/1471-2393-14-330

14. Quispel C, Schneider TA, Hoogendijk WJ et al (2015) Successful five-item triage for the broad spectrum of mental disorders in pregnancy-a validation study. BMC Pregnancy Childbirth. https:// doi.org/10.1186/s12884-015-0480-9

15. Bannatyne AJ, Hughes R, Stapleton P et al (2018) Signs and symptoms of disordered eating in pregnancy: a Delphi consensus study. BMC Pregnancy Childbirth. https://doi.org/10.1186/ s12884-018-1849-3

16. Garner D, Olmstead M, Polivy J (1983) Development and validation of a multidimensional Eating Disorder Inventory for anorexia nervosa and bulimia. Int J Eat Disord. https://doi.org/10.1002/ 1098-108X(198321)2:2\%3c15:AID-EAT2260020203\%3e3.0. $\mathrm{CO} ; 2-6$
17. Tomba E, Tecuta L, Crocetti E et al (2019) Residual eating disorder symptoms and clinical features in remitted and recovered eating disorder patients: a systematic review with meta-analysis. Int J Eat Disord. https://doi.org/10.1002/eat.23095

18. Jebeile H, Gow ML, Baur LA et al (2019) Treatment of obesity, with a dietary component, and eating disorder risk in children and adolescents: a systematic review with meta-analysis. Obes Rev. https://doi.org/10.1111/obr.12866

19. Panão I, Carraça EV (2019) Effects of exercise motivations on body image and eating habits/behaviors: a systematic review. Nutr Diet. https://doi.org/10.1111/1747-0080.12575

20. Gleaves DH, Pearson CA, Ambwani S et al (2014) Measuring eating disorder attitudes and behaviors: a reliability generalization study. J Eat Disord. https://doi.org/10.1186/2050-2974-2-6

21. García E, Fusté A, Mas N et al (2010) Dimensionality of three versions of the Eating Disorder Inventory in adolescent girls. Eur Eat Disord Rev. https://doi.org/10.1002/erv.995

22. Espelage DL, Mazzeo SE, Aggen SH et al (2003) Examining the construct validity of the Eating Disorder Inventory. Assess, Psychol. https://doi.org/10.1037/1040-3590.15.1.71

23. Schoemaker C, Verbraak M, Breteler R et al (1997) The discriminant validity of the Eating Disorder Inventory. Br J Clin Psychol. https://doi.org/10.1111/j.2044-8260.1997.tb01268.x

24. Rathner G, Rumpold G (1994) Convergent validity of the eating disorder inventory and the anorexia nervosa inventory for selfrating in an Austrian nonclinical population. Int J Eat Disord. https://doi.org/10.1002/1098-108X(199412)16:4\%3c381:AIDEAT2260160407\%3e3.0.CO;2-Q

25. Lee $S$, Lee AM, Leung T et al (1997) Psychometric properties of the eating disorders inventory (EDI-1) in a nonclinical Chinese population in Hong Kong. Int J Eat Disord. https://doi.org/10. 1002/(SICI) 1098-108X(199703)21:2\%3c187:AAID-EAT10\% 3e3.0.CO;2-\% 23

26. Túry F, Zs Sáfrán, Wildmann M et al (1997) Az Evési Zavar Kérdőív (Eating Disorder Inventory) hazai adaptációja [Hungarian adaptation of Eating Disorder Inventory]. Szenvedélybetegségek 5:336-342

27. Norring C, Sohlberg S (1988) Eating Disorder Inventory in Sweden: description, cross [HH[Hai adaptációja [Hciója [H[H[HHója [Ha Acta Psychiatr. Scand. https://doi.org/10.1111/j.1600-0447. 1988.tb06386.x

28. Williams RL, Schaefer CA, Shisslak CM et al (1986) Eating attitudes and behaviors in adolescent women: discrimination of normals, dieters, and suspected bulimics using the Eating Attitudes Test and Eating Disorder Inventory. Int J Eat Disord. https://doi. org/10.1002/1098-108X(198607)5:5\%3c879:AID-EAT2260050 $509 \% 3 \mathrm{e} 3.0 . \mathrm{CO} ; 2-8$

29. Holm-Denoma JM, Scaringi V, Gordon KH et al (2009) Eating disorder symptoms among undergraduate varsity athletes, club athletes, independent exercisers, and nonexercisers. Int J Eat Disord. https://doi.org/10.1002/eat.20560

30. Kline RB (1998) Principles and practice of structural equation modeling. Guilford Press, New York

31. Quintana SM, Maxwell SE (1999) Implications of recent developments in structural equation modeling for counseling psychology. Psychol, Couns. https://doi.org/10.1177/0011000099274002

32. Micali N, Treasure J, Simonoff E (2007) Eating disorder symptoms in pregnancy: a longitudinal study of women with recent and past eating disorders and obesity. J Psychosom Res. https://doi. org/10.1016/j.jpsychores.2007.05.003

33. Túry F, Czeglédi E, Papp I et al (2013) A táplálkozási magatartás zavarainak felmérése reprezentatív hazai minta alapján - különös tekintettel a háttértényezőkre [Measuring the prevalence of eating disorders on a representative Hungarian sample - in special consideration of background factors]. In: Susánszky É, Szántó Zs (Eds.): Magyar lelkiállapot 2013 [Hungarian state of mind 
2013]. Budapest, Semmelweis Press, 2013, pp. 147-160. ISBN: ISSN20643721

34. Clark M, Ogden J (1999) The impact of pregnancy on eating behavior and aspects of weight concern. Int J Obes (Lond). https:// doi.org/10.1038/sj.ijo.0800747

35. Lacroix R, Eason E, Melzack R (2000) Nausea and vomiting during pregnancy: a prospective study of its frequency, intensity, and patterns of change. Am J Obstet Gynecol. https://doi.org/10.1016/ S0002-9378(00)70349-8

36. Mason Z, Cooper M, Turner H (2012) The experience of pregnancy in women with history of anorexia nervosa: an interpretive phenomenological analysis. J Behav Addict. https://doi.org/10. 1556/jba.1.2012.2.3
37. Blais MA, Becker AE, Burwell RA et al (2000) Pregnancy: outcome and impact on symptomatology in a cohort of eating-disordered women. Int J Eat Disord. https://doi.org/10.1002/(SICI) 1098-108X(200003)27:2\%3c140:AID-EAT2\%3e3.0.CO;2-E

38. Morgan JF, Lacey JH, Sedgwick PM (1999) Impact of pregnancy on bulimia nervosa. Br J Psychiatry. https://doi.org/10.1192/bjp. 174.2.135

Publisher's Note Springer Nature remains neutral with regard to jurisdictional claims in published maps and institutional affiliations. 